\title{
A modernidade no retrovisor
}

\author{
Patrick Tacussel \\ Doutor; Université Paul-Valéry, Montpellier III \\ tacusselp@aol.com \\ Tradução de Eduardo Portanova Barros ${ }^{1}$ \\ Doutor; PNPD CAPES/PPGCS/Unisinos \\ eduardoportanova@hotmail.com
}

\section{Resumo}

Este artigo trata da questão do termo "pós" relacionado a uma antinomia entre o passado e o futuro que, mesmo sem tomar um rumo, é eminentemente historicista. Procurando vetores de análise dentro de uma esfera de pensamento weberiana, na qual o termo "compreensivo" assume lugar de destaque, o texto defende que vivemos não mais os valores do passado, mas sim como que um novo espírito do tempo. Este tempo não será o do debate ideológico, mas antes o de um reordenamento da polis e, consequentemente, das práticas cotidianas.

\section{Palavras-chave}

Pós-modernidade. História. Cotidiano. Sociologia. Ciências Humanas.

Para Sophia Bouzida "A ideia da modernidade está estritamente correlacionada com o princípio de que é possível e necessário romper com a tradição e de instaurar uma maneira de viver e de pensar absolutamente nova." (LYOTARD, 1986, p. 121, tradução nossa). ${ }^{2}$

A modernidade se manifestou através de um continuum de fases históricas que viu se impor uma de suas formas consideradas pelos seus contemporâneos como sendo irreversíveis. É precisamente esse caráter global e disseminado que permite reconhecer, em cada uma dessas fases, sua potência de atração em escala planetária, com exceção de algumas pequenas porções da humanidade que se mantém parcialmente à margem de sua influência. Weber (1972) foi o primeiro a compreender, tanto em ordem natural quanto social, o início deste processo civilizacional engajado pela intelectualização dos modos de pensar, que en-

\footnotetext{
${ }^{1}$ Colaborou: Olivier Chatriant.

2 "L'idée même de modernité est étroitement corrélée avec le principe qu'il est possible et nécessaire de rompre avec la tradition et d'instaurer une manière de vivre et de penser absolument nouvelle." (LYOTARD, 1986, p. 121).
} 
contraria seu ápice dentro das filosofias da História, nas quais o ponto em comum seria a aspiração de traçar o futuro do gênero humano.

Na sua célebre conferência de 1919 ("A ciência como vocação"), o sociólogo alemão localizou dois momentos que situam, culturalmente, o caminho de destino comum do domínio terrestre. A invenção do conceito, que para Weber (1972, p. 72) foi “[...] um dos maiores instrumentos de todo o conhecimento científico [...]", constituiu, no século V (A.C.), o nascimento distante de uma odisseia cujo berço seria o continente europeu, e que lhe asseguraria, até a metade do século XX, um domínio quase absoluto sobre todas as latitudes. Platão, que na "República" instalou o Filósofo-Rei no mando da cidade e expulsou o poeta para fora de seus muros, consagrou a aliança do saber e do poder, bem como a hierarquização dos sujeitos e de suas faculdades, dentre as quais a mais digna é a do entendimento, apto a desmascarar o sofista e a alcançar a verdade.

A polis é um convite à deliberação em virtude de regras que fixam as normas do estar- junto na solidez das trocas devidamente argumentadas e avaliadas. 0 mito é relegado à evocação do para além do homo faber, mortal e confrontado ao heroísmo de arriscados périplos marítimos e conquistas incessantes que tomam, pouco a pouco, o lugar do homo contemplativus. A verificação das crenças e das superstições múltiplas certamente não desapareceu, mas seu espaço foi seriamente perturbado pela luz que ilumina o escravo extraído da caverna de Platão e de suas sombras, as quais ele considerava como sendo realidades materiais. A segunda etapa é, de acordo com Weber (1972), a experimentação cujo ápice começa com o renascimento, cujas figuras de maior destaque incluem Galileu, Leonardo da Vinci e Francis Bacon. É a passagem da abstração e da generalidade à descoberta e engenhosidade prática de algumas personalidades, condenadas não apenas a buscar as leis da natureza, mas a dedicarem-se, com tenacidade prometeica e sem precedentes, a contorná-las através das ardilosas inovações técnicas até então consideradas insuperáveis. A modernidade só precisava destruir um último ferrolho: a fechadura ainda bloqueada pela estrutura teocrática do poder político.

A dissecação dos cadáveres abria uma via a outras explicações mais perigosas para a ordem estabelecida, e que a Igreja, justamente, havia pressentido. Vasculhando os restos mortais para inventariar suas funções e sua coordenação, corria-se o risco, também, de que ampliar estsa investigação fosse ampliada também à sociedade, desde contanto que apreendida empreendida sob o mesmo ângulo,; reduzindo-a à materialidade que estabelecem asestabelecida pelas articulações ordenadas de acordo com o plano imutável e incognoscível dos 
desígnios da Providência Divina e garantindo a graça concedida a todos os poderes políticos dinásticos. A fórmula de Karl Marx ("o morto se apodera do vivo") toma, aqui, uma dimensão premonitória: a abertura e o exame do corpo humano - embora tenha sido praticado em outros tempos - foi que conduziu, diretamente, à iniciativa mais ousada de que tal procedimento fosse estendido para outro corpo, no qual seria fácil demonstrar quão maior era sua subordinação à inteligência humana do que a um astro: o corpo político, suas instituições, seus modos de legibilidade, sua origem etc.

A Modernidade causará uma mudança epistemológica (não mencionada por Max Weber na conferência de 1919) (WEBER, 1972): Montesquieu será o condutor. Publicando anonimamente, em Genebra Do espírito das leis, no ano de 1748, o Conselheiro do parlamento de Bordeaux - secretamente hostil à monarquia absoluta e preocupado com as reformas que poupariam uma possível revolução violenta - inaugura a filosofia política do Iluminismo, que vai diminuindo durante dois séculos de ideologias liberais. Sob uma perspectiva que naquele momento definia a postura do homem a partir do comprometimento, ele encarna o que ainda não carregava sua marca de referência antecipatória: a vanguarda. Seu ensaio soa como um aviso para as autoridades da época e se apresenta como um exame robusto dos males que ameaçam o descuidado soberano, desdenhoso de dados objetivos sobre os quais repousa seu governo. Ao longo dos capítulos, ele trai seus sentimentos e inclinações: como Maquiavel - do qual é menos próximo intelectualmente -, ele partilhava a ambição de ser escutado em virtude de uma inteligência nova, que transformava os antigos oráculos e suas previsões baseando-as na experiência do presente e da historiografia revisitada em um passado acessível para aqueles que conhecem as leis do desenvolvimento dos povos diante do desafio de seu desaparecimento. ${ }^{3}$

A obra Do espírito das leis (MONTESQUIEU, 1748), precursora de um gênero literário (o Samizdat), é ao mesmo tempo um estudo que pretende fundar a possibilidade de pôr à prova a evidência causal das leis da natureza inorgânica no meio administrado pelos homens e tirar conclusões sobre os valores e as virtudes morais dos habitantes de um território. Para que tal perspectiva fosse válida, o autor arriscou uma política maior: procurar o espírito das leis a partir de dados históricos, demográficos ou geográficos, supondo que eles fossem uma consequência e que estivessem em concordância com as leis do espírito, aquele acordo da evolução dos homens em um território, um tempo indexado na cultura. Nesta fase

\footnotetext{
${ }^{3}$ A respeito desse tema eu remeto ao estudo estimulante de Colonomos (2014) A política dos oráculos: contar o futuro hoje (tradução livre).
} 
da sua reflexão, Montesquieu (1748) remove, de facto, o projeto inescrutável de algum capricho ou de injunções divinas em assuntos mundanos. Deus é acionado pelo espírito da lei, porque nenhuma das linhas do autor teria qualquer sentido se viesse de uma inteligibilidade capaz de se apresentar como edificação voluntária; o paciente trabalho de um legislador iluminado por sua consciência. A modernidade entra em uma tensão que leva ao paroxismo sua herança monocéfala da transmissão do poder político, cuja legitimidade repousa na exceção soberana, separada de tudo o que constitui a sociedade e da ameaça de destruí-la através de uma ruptura que liga a cabeça ao corpo místico daquilo que se tornará a nação.

A Revolução Francesa, saudada por Kant em Königsberg, é o evento que inaugura a emergência moderna da política e do processo de secularização das instituições a cargo dos Estados. A transcendência característica da autoridade do Antigo é eliminada para o benefício da imanência do povo que reúne cidadãos, membros contratuais do estado-nação. A força desse cenário encontra-se na missão universal que faz de seus porta-bandeiras os depositários de valores superiores às circunstâncias históricas específicas da Revolução Francesa e da queda da monarquia capetiana. ${ }^{4}$ A Declaração Universal dos Direitos do Homem, tradução filosófico-jurídica de aufklärung, é inseparável de uma ideologia centrada sobre uma ideia de progresso moral que a administração pública deveria tornar concreta.

A grande história da era moderna passa dos construtores teóricos e seus princípios conceituais às gerações incumbidas, sob a liderança daqueles, do seu desempenho na tarefa que tem diante de si, a de oferecer aos seus filhos mais do que eles receberam de seus antepassados. A imortalidade subjetiva será, nos textos de Auguste Comte, a expressão dessa solidariedade que fortalece cada indivíduo no dever sagrado de se subordinar com "sábia resignação" (sic) a tudo o que constitui o presente que seus sucessores deverão, no mesmo espírito, aumentar em valor. 0 legado do futuro vai ditar todo o comportamento social: a vontade de empreender no plano econômico, o engajamento político e militante, a ação moral individual e coletiva, as práticas artísticas e literárias que repousam na ruptura com as formas caídas dos gostos do passado, impondo sobre o choque de suas criações uma nova ordem de representação da realidade.

A modernidade tinha tudo o que era preciso para ver florescer uma mitologia na exata medida de sua vertigem demiúrgica: a de um mundo no qual cada evento é, também, uma finalidade indexada em um futuro que lhe dá o seu significado essencial. Seria bastante difícil compreender o conceito de progresso sem levar em conta o padrão mental que reconfi-

${ }^{4}$ N.T.: Dinastia de reis da França iniciada por Hugues Capet, entre 987-996, do qual deriva o nome. 
gura as relações dentro das quais se disputam as também relações de consciência acerca dos registros da época. Em outras palavras, entre o necessário e o possível, a racionalização irá estender a sua influência em todas as esferas da vida, ao passo que a técnica é uma extensão da vontade laboriosa, livre de qualquer escrúpulo ético no âmbito da sua realização.

É o que Weber aponta com uma inquietude não dissimulada: "A intelectualização e a racionalização crescentes não significam, de jeito algum, um crescente conhecimento geral das condições sob as quais nós vivemos." (WEBER, 1972, p. 70, tradução nossa) ${ }^{5}$. A sequência dessa proposição indica a origem do que o sociólogo alemão, não desprovido de ceticismo, teme em seu julgamento. Os modos racionalizados da vida administrada que englobam todos os aspectos da relação do homem civilizado com suas fronteiras conhecidas, acoplados à primazia dada aos poderes intelectuais sobre todos os outros, conduzem a um espírito novo. Significam:

[...] que nós sabemos ou cremos que a cada instante poderíamos, desde que o quiséssemos, comprovar que não existe em princípio nenhuma potência misteriosa e imprevisível que interfere no curso da vida; logo, que podemos dominar qualquer coisa pela previsão." (WEBER, 1972, p. 70, tradução nossa). ${ }^{6}$

Todos os termos desta frase merecem atenção: a modernidade é uma paisagem sobre a qual o poder condiciona uma potência que neste momento oferece ao homem a possibilidade de reduzir às coisas previsíveis tudo o que é real. Enquanto Durkheim nos convida a considerar os fatos sociais como coisas, ou seja, traduz o mundo vivido nas formas em termos de reificação, garantindo sua objetivação científica, Weber (1972) acrescenta um aspecto essencial a esse postulado epistemológico: a dimensão do futuro social e histórico controlável pelos prodígios da tecnociência.

A Revolução Industrial selou o destino da modernidade: o capitalismo é o vetor de sua expansão, e trata de transformar o conceito de salvação. Dentro de poucos anos, todas as velhas distinções irão quebrar, uma vez que o capital financeiro vem para controlar o movimento da massa humana nos territórios de sua produtividade mais competitiva; o rosto do homem assume os traços de estrangeiro e imigrante, e sua identidade se confunde com uma mala em que sua história pessoal e familiar, sua cultura e memória de seu país se perdem em uma transmissão impossível, uma língua suspensa em palavras e expressões resgatadas

\footnotetext{
5 "L'intellectualisation et la rationalisation croissantes ne signifient nullement une connaissance générale croissante des conditions dans lesquelles nous vivons."

6 "[...] que nous savons ou que nous croyons qu'à chaque instant nous pourrions, pourvu seulement que nous le voulions, nous prouver qu'il n'existe en principe aucune puissance mystérieuse et imprévisible qui interfère dans le cours de la vie ; bref que nous pouvons maîtriser toute chose par la prévision".
} 
do esquecimento. Simmel foi um dos observadores mais atentos desse fenômeno que, segundo ele, afeta tanto os sentidos (olfato, audição, visão, tato, paladar) quanto à percepção dos antigos lugares de uma cultura excepcional, como Roma, Florença e Veneza. Ansioso para preservar as características individuais, em "[...] a equação entre mim e o mundo [...]" (SIMMEL, 1989, p. 290) sua análise se depara com as contradições da modernidade, na qual Benjamin (1982) será o espeleólogo audacioso na Passagenwerk. Em seu exílio em Paris, este último fornece uma observação perspicaz que sua solidão não negou: a dissolução inevitável da individualidade burguesa na mercadoria, constantemente empurrando a mão de seu produtor, abandonando-o na fantasmagoria museológica ${ }^{7}$ do consumo de massa.

0 pós-moderno destaca outra relação entre passado-presente, assentada, desta vez, sobre a descoberta de uma historicidade paradoxal, não mais linear, mas descontinuísta. Nesta perspectiva, não é de estranhar que as referências essenciais da Modernidade, como a História, a Razão, o Progresso e o Projeto, tornaram-se os avatares ideais de tronos desvalorizados. Se as filosofias da história foram enxertadas do tempo linear é porque, do mesmo modo, foram os primeiros sistemas de antecipação construídos e propostos em nome de uma ruptura com o "ontem eterno" (WEBER, 1972). O pós-moderno não exclui a história, mas concebe-a a partir do que Heidegger chamou de historial, isto é, a partir de uma temporalidade que desenvolve um "esquecimento originário". Por esta razão, a história e o tempo destacam, para os teóricos da pós-modernidade, um processo de análise, uma anamnese, uma anamorfose, uma analogia. Surge então a necessidade de examinar a relação entre tradição e historicidade, bem como as formas de comunicação que estabelecem essa relação, que é o que Lyotard (1986) tenta nos mostrar no capítulo seis de A condição pós-moderna: Pragmática do saber narrativo.

A realização desta historicidade paradoxal implica a articulação do espaço e do tempo de uma forma menos homogênea do que aquela tecida pela modernidade (aqui entendida como weltanschauung), o melancólico é a figura de ontem dessa lucidez: é a experiência interior da heterogeneidade do espaço e do tempo, que busca reconhecer, simultaneamente, correspondências que reporiam, tanto o sentido da sua existência quanto de sua experiência, em uma unidade original, mascarada pela unificação forçada da civilização industrial que degrada o refinamento dos nossos sentimentos em benefício de sua multiplicação efêmera (ver o tema do "uniteísmo" por Charles Fourier). A melancolia é imersa em um arquipélago de cultura; tenta navegar no espaço-espaço, a fim de recuperá-lo como a configura-

${ }^{7}$ N.T.: No original, "muséal”, neologismo derivado de museu. 
ção da quantidade de memória individual e coletiva, sem a qual o ser se rende à artificialidade das coisas, a pequena realidade.

Em seus comentários sobre Charles Baudelaire, Benjamin (1982, p. 216) observou: "Escrever a história significa dar sua fisionomia às datas". Sua perspectiva sobre o mundo é icônica, e talvez irônica, pelo fato de o autor ser guiado pela visão e o universo tornar-se um caleidoscópio cujas imagens são como muitas mesas para decifrar (ver "Les tableaux parisiens", de Baudelaire). Se a melancolia consegue decifrar a modernidade é porque a sua consciência está em dessincronia constante com a hierarquia temporal, que dá ao novo, ao romance, um papel essencial na corte moderna (progressista) da duração. A melancolia compreende a correspondência na qual o homem moderno está considerando a superação sem perceber o déjà vu: "[0] spleen leva séculos entre o agora e aquele que tem sido experimentado. É ele que, incansavelmente, produz a 'antiguidade'.” (BENJAMIN, 1982, p. 13). Entre a melancolia e a condição pós-moderna, é a busca de uma "outra totalidade" que está em jogo. Não é mais uma totalidade dialética, que sempre superando as contradições que a constitui e "hipostasiando" a história sob o pretexto de autodeterminação do Espírito Absoluto, ou na síntese de classe social universal, mas sim um todo sintético, aquele das correspondências entre os elementos heterogêneos que o compõem e do murmúrio do passado, lembrando-se das concepções de experiência que vestem os rudimentos culturais em face ao desencantamento do mundo.

O pós-moderno não significa, pois, o fim da modernidade, mas a ideia de que a modernidade, como fim, se baseia sobre um entendimento parcial da realidade histórica, dada como uma hipótese abstrata e inquestionável. 0 que muda é o agenciamento de sequências temporais a partir das quais estávamos apreendendo o presente e a percepção do futuro. Neste contexto, a inovação deixa de ser o resultado de uma ruptura ou crítica do que é antigo; não se deve confundir o futuro com um rosto seguro de emancipação e de sua projeção antecipada.

0 pós-moderno indica, assim, o tempo da simultaneidade. A nossa experiência de temporalidade adquire densidade contemporânea; uma presença em tempo real no mundo. Gianni Vattimo compartilha essa observação para mostrar que a sequência de eventos e informações se cruzam. A proliferação simultânea de perspectivas interpretativas leva a uma espacialização do tempo, um declínio do choque de um colapso mental que, uma vez, poderia criar uma obra de arte (moderna) como as mais notáveis do passado (ver Marx e seus pensamentos sobre arte grega nos Manuscritos de 1844). A isso, o fato histórico atual é 
em si similar - não sem opacidade, talvez - mas na transparência cegante, se não paradoxal, dna proliferação de suas leituras tornadas antagonistas. ${ }^{8}$

Os críticos da pós-modernidade, em geral, são pouco instruídos sobre o que ela recobreabarca. 0 contingente desprovido desse conhecimento afirma que este conceito iria deixarabriria espaço o campo livre para um relativismo sem freio,. pPouco importando aos seus olhos, cobertos de ignorância, que o relativismo tinha sido, inicialmente, defendido por pensadores modernos - Simmel (1989), por exemplo - e que, neste contexto, o relativismo epistemológico, obviamenteevidentemente, não trata da hierarquia dos valores morais: os proponentes de teorias pós-modernas nunca disseram que tudo se dá apenas eticamente, mas apenas somente que os contextos de apreensão do justo, do bom, do verdadeiro e do belo jamais saíram do exercício de um julgamento circunstanciado. Na verdade, não há nada a que provear, por um esforço intelectual, que essas categorias derivaram de uma universalidade normativa, fixada de uma vez por todas. A emoção estética despertada por uma obra sublime, (no sentido kantiano) da pintura, ou da música ou, da arte poética, é intensa para um contemporâneo de Mozart ou Péricles, mas a sua interioridade psíquica, a sua recepção cultural, é marcada por um ambiente que enquadra as formas da sensibilidade, a cada vez, em uma articulação específica. Este grupo de detratores da pós-modernidade não tem outra escolha do , se não que usar o nome da Razão, na sob a qual cada domínio de intervenção e de legitimidade obedece aos princípios semelhantes, o que confirmaconfirmando assim o progresso de setores do espírito humano que agem sobre a natureza e a vida organizada. Essa alucinação intelectual não resiste a experimentar o cotidiano no qual as esferas são habitadas pelo jogo de relações entre consciências: de facto, racionalidades são relativas e tensionadas em relação às objetivações que não apontam para qualquer solo ontológico, como identificações plurais, sobre as quaiscomo salientado por Maffesoli (1990) salientou quanto ao jogo, proposta teórica que irá alimentar futuros estudos empíricos diretamente envolvidos com ele. Que as racionalidades sejam múltiplas e que marquem o fim de uma razão histórica imperial e administrada por uma lógica de Estado, isso parece óbvio: o comerciante que passa horas realizando transações financeiras na internet é ainda ele mesmo quando pensa na galante refeição para a qual vai convidar alguém que deseja conquistar?

\footnotetext{
${ }^{8}$ Sobre a abordagem de Vattimo $(1987,1990,1997)$ a respeito da pós-modernidade, remeto às seguintes obras: La fin de la modernité; La société transparente; Au-delà de l'interprétation: la signification de l'herméneutique pour la philosophie.
} 
Não se trata de fazer um inventário do Iluminismo do qual as influências, tanto filosóficas quanto culturais, são apenas nostalgia, mas de encontrar uma relação orgânica entre o sujeito e o seu ecossistema, isto é, estabelecer um pacto no sentido de uma ecosofia ${ }^{9}$, para estabelecer um pacto entre o apoio e a sociabilidade de um poder para as muitas ordens de autoridades que estão tentando minar. É sob este novo ângulo que devemos examinar os novos conflitos sociais nas sociedades pós-modernas que operam nos grupos horizontais, ignorando qualquer dominação hierárquica dentro deles, organizando-se a partir da web e guiando-sedos pelo tempo presente de suas ações reivindicativas. Os recursos às ideologias políticas historicistas são o forte de pequenos grupos e suas ações pitorescas, especialmente como em algumas referências antes majestosas e envolventes - como o socialismo -, o que não significa que a marca de um partido se preocupepa em aprofundar um conteúdo autêntico. Em última análise, é o esgotamento da democracia representativa, nascida da plebis secessio, a divisão das elites, dos eleitos e do povo, que se acentua na cenografia do espaço público. No entanto, é permitido observar os valores e práticas inovadoras em todas as áreas da vida social que tendem a reconfigurar a partilha dos horizontes na existência contemporânea.

\section{Referências}

BAUDELAIRE, Charles. Les fleurs du mal. Paris: Le Livre Poche, 1972.

BENJAMIN, Walter. Zentral Park. Revue d'Esthétique, Toulous, n. 1, 1981.

BENJAMIN, Walter. Charles Baudelaire: un poète lyrique à l'apogée du capitalisme. Paris: Payot, 1982.

COLONOMOS, Ariel. La politique des oracles: raconter le futur aujourd'hui. Paris: Albin Michel, 2014.

LYOTARD, Jean-François. Le postmoderne expliqué aux enfants. Paris: Galilée, 1986.

MAFFESOLI, Michel. Au creux des apparences. Paris : Plon, 1990.

MONTESQUIEU, Charles Louis de. Défense de l'Esprit de loix, à laquelle ou a joint quelques éclaircissemens. Genève: Barrillot, 1748.

SIMMEL, Georg. Philosophie de la modernité. Paris: Payot, 1989.

${ }^{9}$ N.T.: Neologismo que reúne os termos ecologia e filosofia. 
VATTIMO, Gianni. Au-delà de l'interprétation: la signification de l'herméneutique pour la philosophie. Bruxelles: De Boeck Université, 1997.

VATTIMO, Gianni. La fin de la modernité. Paris: Editions du Seuil, 1987.

VATTIMO, Gianni. La société transparente. Paris: Desclée de Brouwer, 1990.

WEBER, Max. Le savant et le politique. Paris: 10/18, 1972.

\title{
Modernity in the rear-view
}

\begin{abstract}
This article is about the term post related to a contradiction between the past and the future that is eminently historicist even without taking a direction. Looking for vectors of analysis within a Weberian perspective in which the comprehensive term takes a prominent place, the text argues the thesis that we no longer live the values of the past, but with a new spirit of the times. This age will not be of the ideological debate, but rather of a reordering of the polis and, therefore, of the daily practices.
\end{abstract}

\section{Keywords}

Postmodernity. History. Quotidian. Sociology. Humanities.

Recebido em 26/02/2016

Aceito em 28/02/2016 